\title{
Kandungan 10 Jenis Logam Berat pada Daging Ikan Sapu-Sapu (Pterygoplichthys pardalis) Asal Sungai Ciliwung Wilayah Jakarta
}

\author{
Laksmi Nurul Ismi $^{1 *}$, Dewi Elfidasari ${ }^{1}$, Riris Lindiawati Puspitasari ${ }^{1}$, Irawan Sugoro² \\ ${ }^{1}$ Program Studi Biologi, Fakultas Sains dan Teknologi, Universitas Al Azhar Indonesia, \\ Komplek Masjid Agung Al Azhar, Jl. Sisingamangaraja, Jakarta Selatan 12110 \\ ${ }^{2}$ Pusat Aplikasi Isotop dan Radiasi (PAIR), Badan Tenaga Nuklir Nasional (BATAN), \\ J1. Lebak Bulus Raya No 49, Jakarta 12440
}

Penulis untuk Korespondensi/E-mail: laksminrlism@gmail.com

\begin{abstract}
Abstrak - Ikan Sapu-Sapu (Pterygoplichthys pardalis) salah satu jenis ikan yang berada di sungai Ciliwung MT. Haryono Jakarta. Ikan tersebut mampu hidup dalam perairan sungai Ciliwung yang tercemar oleh logam. Masyarakat sekitar memanfaatkan ikan sapu-sapu sebagai produk olahan pangan. Permasalahannya apabila ikan sapu-sapu yang diolah tersebut tercemar oleh logam maka dapat membahayakan masyarakat. Analisis kandungan logam dilakukan dengan menggunakan alat Spekrometer X-Ray Fluoresence (XRF). Hasil penelitian menunjukan bahwa ikan sapu-sapu tersebut mengandung logam As, Cd, Co, Cr, Fe, Mn, Hg, Ag, Pb dan Zn. Terdapat empat logam yang dibandingkan dengan PerBPOM 2017 yaitu $\mathrm{As}, \mathrm{Hg}$, Pb dan $\mathrm{Cd}$. Keempat logam tersebut telah melebihi batas maksimum yang telah ditetapkan. Sehingga ikan sapu-sapu asal sungai Ciliwung MT.Haryono tidak layak untuk dikonsumsi oleh masyarakat.
\end{abstract}

Abstract - Plecofish (Pterygoplichthys pardalis) is one type of fish that is on the Ciliwung river MT. Haryono Jakarta. The fish is able to live in waters of the Ciliwung river which is polluted by metals. The surrounding community uses plecofish as a processed food product. The problem is that if the pleco flesh that are processed are contaminated by metals, they can risky the community. Analysis of metal content was carried out using the X-Ray Fluorescence (XRF) spectrometer. The results showed that the pleco flesh contained metals $\mathrm{As}, \mathrm{Cd}, \mathrm{Co}, \mathrm{Cr}, \mathrm{Fe}, \mathrm{Mn}, \mathrm{Hg}, \mathrm{Ag}, \mathrm{Pb}$ and $\mathrm{Zn}$. There is four metals compared with PerBPOM 2017 are As, $\mathrm{Hg}, \mathrm{Pb}$ and $\mathrm{Cd}$. The four metals have exceed the maximum specified threshold. So the pleco flesh from the Ciliwung river MT. Haryono are not worth for consumption by the community.

Keywords - Ciliwung river, Pleco fish, Metal, and Spektrometer X-Ray Fluoresence

\section{PENDAHULUAN}

$\mathrm{K}$ ota Jakarta saat ini dilintasi oleh 13 sungai, salah satunya adalah sungai Ciliwung. Sungai Ciliwung berasal dari kaki Gunung Pangrango mengalir ke arah Jakarta dan bermuara ke Teluk Jakarta. Sungai Ciliwung memiliki fungsi penting bagi kehidupan masyarakat sekitarnya. Mengingat aktivitas manusia di sekitar sungai Ciliwung semakin beragam, menjadikan sungai Ciliwung semakin tercemar dari waktu ke waktu. Logam berat telah terdeteksi di sungai Ciliwung [1]. Logam berat tersebut dapat terakumulasi di dalam organ tubuh seperti daging atau otot dan hati biota sungai.
Terakumulasinya suatu logam dalam jangka waktu lama dapat menjadi racun.

Di sungai Ciliwung terdapat biota sungai seperti krustasea, amfibi, reptil dan ikan. Ikan sapu-sapu merupakan salah satu dari biota yang terdapat di DAS Ciliwung [2]. Seperti kita ketahui bahwa sungai Ciliwung yang telah tercemar akan mempengaruhi kehidupan biota yang ada di sungai tersebut termasuk ikan sapu-sapu. Menurut [3] dan warga sekitar, saat ini ikan sapu-sapu asal sungai Ciliwung banyak dimanfaatkan oleh pedagang atau penjual makanan untuk dijadikan sebagai produk bahan baku olahan. Sungai Ciliwung yang tercemar 
oleh logam akan menyebabkan akumulasi logam pada ikan sapu-sapu yang hidup di sungai tersebut dan berpotensi membahayakan bagi kesehatan masyarakat yang mengkonsumsinya. Sebagai contoh, hasil penelitian tentang kandungan logam berat timbal $(\mathrm{Pb})$, Mercuri $(\mathrm{Hg})$ dan Cadmium $(\mathrm{Cd})$ pada daging ikan sapu-sapu (Hyposarcus pardalis) di sungai Ciliwung stasiun Srengseng, Condet dan Manggarai didapatkan bahwa daging ikan sapu-sapu mengandung ketiga logam berat $\mathrm{Pb}, \mathrm{Hg}$, dan $\mathrm{Cd}$ [4].

Oleh karena itu penelitian ini dilakukan untuk mendeteksi keberadaan 10 jenis logam berat yang terkandung pada daging ikan sapu-sapu di sungai Ciliwung. Tujuan dari penelitian ini adalah menganalisis kandungan 10 logam berat yang terdapat pada ikan sapu-sapu ( $P$. pardalis) di sungai Ciliwung.

\section{METODE}

\section{Alat dan bahan}

Alat yang digunakan saat sampling meliputi kontainer dan jaring. Alat yang digunakan di laboratorium yaitu pisau, gunting, penggaris dengan ketelitian $1 \mathrm{~mm}$, wadah, blender, saringan \pm 100 mesh, oven $60^{\circ} \mathrm{C}$, neraca analitik [Sartorius] dengan ketelitian $0,0001 \mathrm{~g}$, plastik ziplock ukuran $6 \times 8 \mathrm{~cm}$, desikator [Duran Normax], sudip, cawan krus, penjepit cawan krus dan alat $X$-Ray Fluoresence (XRF). Bahan-bahan yang digunakan yaitu 18 ekor ikan sapu-sapu.

\section{Pengumpulan sampel}

Pengumpulan sampel dilakukan pada bulan Agustus-September 2017 dengan melakukan survei ke lapangan untuk memperoleh informasi tentang asal ikan sapu-sapu dan lingkungannya yang berlokasi di DAS Ciliwung MT Haryono MT Gg. Ciliwung, Cawang, Jakarta Pusat dengan titik koordinat garis bujur $6^{\circ} 14^{\prime} 36.50$ "S dan garis lintang $106^{\circ} 51^{\prime} 45.03 " E$. Ikan sapu-sapu ditangkap menggunakan jaring, kemudian dimasukkan ke dalam kontainer. Selanjutnya ikan tersebut dibawa ke Laboratorium Biologi BATAN untuk dilakukan pengukuran morfometrik ikan meliputi panjang total, lebar total, tinggi total dan bobot total ikan sapu-sapu.

\section{Preparasi sampel}

Daging ikan sapu-sapu dipisahkan dari tulang dan kulitnya menggunakan teknik fillet. Daging ditempatkan pada cawan krus lalu dikeringkan dalam oven bersuhu $60^{\circ} \mathrm{C}$ selama lima hari. Setelah ikan tersebut kering, selanjutnya ditimbang menggunakan neraca digital lalu digerus dan dimasukkan dalam plastik ziplock. Sampel yang sudah digerus kemudian diayak dengan ayakan berukuran 100 mesh. Sampel yang sudah diayak kemudian dimasukkan ke dalam oven $105^{\circ} \mathrm{C}$ selama dua jam dan dibiarkan dingin. Setelah dingin, sampel tersebut ditimbang masing-masing 5 gram dan dimasukkan ke dalam cup.

\section{Analisis kandungan logam}

Analisis kandungan logam ikan sapu-sapu menggunakan alat X-Ray Fluoresence (XRF) Spectrometer. Sampel cup diletakan ke dalam chamber XRF, diukur pada 8 dan $12 \mathrm{KV}$ dengan intensitas 0,32-0,34 mA. Hasil dari analisis berupa print out data komposissi dan kandungan logam dalam daging ikan sapu-sapu. Proses analisis kandungan ligam berat dilakukan di PTBGN BATAN.

\section{HASIL DAN PEMBAHASAN}

Sampel daging ikan sapu-sapu yang dianalisis dalam penelitian ini terlebih dahulu dilakukan dengan pengovenan untuk menghilangkan kadar air dan dibuat serbuk untuk memudahkan dalam proses analisis berikutnya. Hasil analisis XRF menunjukkan nilai konsentrasi dalam satuan ppm. Berdasarkan hasil analisis diketahui bahwa pada daging ikan sapu-sapu tersebut terdapat 10 jenis logam (Tabel 1).

Tabel 1. Kandungan logam pada daging ikan sapu-sapu

\begin{tabular}{|c|c|c|c|}
\hline \multirow[t]{2}{*}{ No } & \multirow[t]{2}{*}{ Logam } & \multicolumn{2}{|c|}{ Konsentrasi (mg/kg) } \\
\hline & & Hasil & PerBPOM \\
\hline 1 & As (Arsen) & $0,7 \pm 0$ & 0,25 \\
\hline 2 & Cd (Kadmium) & $0,5 \pm 0,2$ & 0,1 \\
\hline 3 & Co (Kobalt) & $3,8 \pm 0$ & \\
\hline 4 & $\mathrm{Cr}$ (Krom) & $2,3 \pm 0,2$ & - \\
\hline 5 & Sn (Timah) & $10,1 \pm 0,3$ & - \\
\hline 6 & Mn (Mangan) & $10,1 \pm 0,3$ & - \\
\hline 7 & Hg (Merkuri) & $0,3 \pm 0,3$ & 0,06 \\
\hline 8 & Ag (Argentum) & $0,5 \pm 0$ & - \\
\hline 9 & Pb (Timbal) & $2,2 \pm 0,03$ & $\mathbf{0 , 1 0}$ \\
\hline 10 & Zn (Zink) & $61,8 \pm 0,7$ & - \\
\hline
\end{tabular}

Keberadaan logam dalam tubuh organisme terjadi karena adanya akumulasi logam pada organisme tersebut. Terdapat dua mekanisme masuknya logam ke dalam tubuh makhluk hidup, yaitu secara langsung dan tidak langsung [5].

Kandungan logam yang berada pada daging ikan sapu-sapu tersebut dapat dikaji dan dibandingkan 
dengan standar ketentuan Peraturan Badan Pengawas Obat Dan Makaan Republik Indonesia (PerBPOM RI) Nomor 23 Tahun 2017 tentang Batas Maksimum Cemaran Logam Berat Dalam Pangan Olahan. Berdasarkan Peraturan Badan Pengawas Obat Dan Makaan Republik Indonesia (PerBPOM RI) Nomor 23 Tahun 2017 pada pasal 2 bahwa persyaratan keamanan pangan olahan harus memenuhi batas maksimum cemaran logam berat. Cemaran logam berat yang dimaksud meliputi: arsen $(\mathrm{As})$, timbal $(\mathrm{Pb})$, kadmium $(\mathrm{Cd})$, merkuri $(\mathrm{Hg})$ dan timah (Sn). Sehingga dari hasil penelitian yang diperoleh hanya 5 logam berat saja yang dapat dikaji dan dibandingkan dengan PerBPOM RI Nomor 23 Tahun 2017 yaitu As, Cd, Sn, Hg, dan Pb.

Hasil analisis yang didapatkan menunjukkan bahwa pada daging ikan sapu-sapu terdapat logam As dengan konsentrasi sebesar $\mathbf{0 , 7 \pm 0} \mathbf{~ m g} / \mathbf{k g}$ dan melebihi nilai ambang batas (NAB) [6] yaitu $\mathbf{0 , 2 5}$ $\mathbf{m g} / \mathbf{k g}$. Nilai As yang tinggi dapat berakibat buruk terhadap mata, kulit, darah dan liver. Efek arsenik juga dapat menyebabkan kegagalan fungsi tulang dan terjadinya pancytopenia yaitu menurunnya jumlah sel darah perifer [7].

Kandungan logam Cd pada daging ikan sapu-sapu memiliki konsentrasi sebesar $\mathbf{0 , 5} \pm \mathbf{0 , 2} \mathbf{~ m g / k g}$ melebihi nilai ambang batas (NAB) [6] yaitu 0,10 $\mathbf{m g} / \mathbf{k g}$. Nilai yang didapatkan lebih tinggi dibandingan dengan PerBPOM. Menurut [7], Gejala umum keracunan $\mathrm{Cd}$ adalah sakit di dada, nafas sesak, batuk-batuk dan lemah. Perkiraan dosis mematikan (lethal dose) akut adalah sekitar 500 $\mathrm{mg} / \mathrm{kg}$ untuk dewasa dan efek dosis akan nampak jika terabsobsi $0.043 \mathrm{mg} / \mathrm{kg}$ perhari menurut Ware 1989 [7].

Kandungan logam Sn pada daging ikan sapu-sapu hasil penelitian memiliki konsentrasi sebesar $10,1 \pm 0,3 \mathrm{mg} / \mathrm{kg}$, nilai regulasi nilai ambang batas (NAB) mengenai $\mathrm{Sn}$ sebagai bahan pangan perikanan tidak disebutkan dalam [6]. Namun demikian apabila ditinjau dari pangan olahan lain yang tidak dikemas dalam kaleng nilai ambang batas (NAB) yaitu $40 \mathrm{mg} / \mathrm{kg}$ [6]. Dengan demikan dapat diasumsikan bahwa kandungan logam Sn pada daging ikan sapu-sapu masih dibawah nilai ambang batas (NAB).

Logam $\mathrm{Hg}$ pada daging ikan sapu-sapu hasil penelitian memiliki konsentrasi sebesar $\mathbf{0 , 3} \pm \mathbf{0 , 3}$ $\mathbf{m g} / \mathbf{k g}$ melebihi nilai ambang batas (NAB) [6] yaitu 0,06 mg/kg. Hg merupakan logam berat yang menduduki urutan pertama dalam sifat racunnya dibandingakan dengan $\mathrm{As}, \mathrm{Cd}$ dan $\mathrm{Pb}$. Keracunan $\mathrm{Hg}$ yang akut dapat menyebabkan terjadinya kerusakan saluran pencernaan, gangguan kardiovasculer, kegagalan ginjal akut maupun shock [7].

Kandungan logam $\mathrm{Pb}$ memiliki konsentrasi sebesar $\mathbf{2 , 2 \pm 0 , 0 3 ~} \mathbf{~ m g} / \mathbf{k g}$ melebihi nilai ambang batas (NAB) [6] yaitu $\mathbf{0 , 2 0} \mathbf{~ m g} / \mathbf{k g}$. Paparan bahan tercemar logam $\mathrm{Pb}$ dapat menyebabkan gangguan pada organ neurologi, fungsi ginjal, sistem repoduksi, sistem syaraf, sistem dan hemopoitik [7]. Dengan demikian dapat diasumsikan bahwa jika logam $\mathrm{Pb}$ yang dikonsumsi dari daging ikan sapu-sapu tersebut mengandung logam $\mathrm{Pb}$ yang sudah melebihi NAB maka dapat mempengaruhi kesehatan tubuh manusia.

Tinggi kandungan logam (As, $\mathrm{Cd}, \mathrm{Hg}$ dan $\mathrm{Pb}$ ) pada daging ikan diduga karena adanya akumulasi ligam akibat tingginya cemaran logam di air dan disedimen. Berdasarkan hasil penelitian [8], bahwa kandungan rata-rata kandungan logam tertinggi terjadi saat musim hujan serta akibat akumulasi dari air dan sedimen. Selain itu, berdasarkan hasil observasi yang dilakukan sepanjang bantaran Ciliwung ditemukan adanya beberapa industri dan pemukiman warga yang beraktivitas di bantaran sungai Ciliwung. Sebagai daerah yang dilalui sungai Ciliwung, kegiatan industri tersebut dapat mempengaruhi peningkatan pencemaran sungai. Hal ini didukung oleh hasil penelitian [9].

\section{KESIMPULAN}

Kandungan logam berat $\mathrm{As}, \mathrm{Cd}, \mathrm{Hg}$ dan $\mathrm{Pb}$ pada daging ikan sapu-sapu di sungai Ciliwung telah melewati batas maksimum untuk produk daging perikanan yang ditetapkan oleh BPOM 2017. Kandungan logam berat tertinggi pada daging ikan sapu-sapu yaitu logam berat $\mathrm{Pb}$ (timbal) sebesar $\mathbf{2 , 2 \pm 0 , 0 3}$. Sehingga, ikan sapu-sapu yang berasal dari sungai Ciliwung wilayah Jakarta tidak layak konsumsi atau menjadi bahan olahan pangan.

\section{UCAPAN TERIMAKASIH}

Terima kasih kami sampaikan kepada Kementerian Riset dan Teknlogi Pendidikan Tinggi atas dana Penelitian tahun 2018 pada skema Penelitian Unggulan Perguruan Tinggi (PTUPT), LP2M UAI atas bantuan dana TA 2017-2018, rekan-rekan 
peneliti dan staf di Laboratorium PAIR \& PTBGN BATAN Pasar Jumat.

\section{REFERENSI}

[1] S. Yudo, "Kondisi pencemaran logam berat di perairan sungai DKI Jakarta," Jurnal Air Indonesia, pp. 2(1): 1-15, 2006.

[2] D. Wowor, "Studi biota perairan dan herpetofauna di daerah aliran sungai (DAS) Ciliwung dan Cisadane: kajian hilangnya keanekaragaman hayati.," Laporan Penelitian. Puslit Biologi LIPI, Bogor, p. 48, 2010.

[3] Aiman, "Telusuri Ikan Sapu-sapu yang Jadi Bahan "Siomay"," 2016. [Online]. Available: http://megapolitan.kompas.com/read/2016/09/ 05/19275601/aiman.malam.ini.telusuri.ikan.sa pu-sapu.yang.jadi.bahan.siomay. [Diakses 10 Maret 2018].

[4] N. A. Ratmini, "Kandungan Logam Berat Timbal $(\mathrm{Pb})$, Mercuri (Hg), Dan Cadmium (Cd) Pada Daging Ikan Sapu-Sapu (Hyposarcus pardalis) Di Sungai Ciliwung Stasiun Srengseng, Condet, Dan Manggarai," VIS VITALIS, pp. 2(1):1-7, 2009.

[5] R. Puspasari, "Logam dalam Ekosistem Perairan,” J. BAWAL, pp. 1(2): 43-47, 2006.

[6] PerBPOM RI, Tentang Batasan Maksimum Cemaran Logam Berat Dalam Pangan Olahan Nomer 23 Tahun 2017, DKI Jakarta, 2017.

[7] J. Sudarmaji, Mukono dan Corie, "Toksikologi Logam Berat B3 Dan Dampaknya Bagi Kesehatan," Jurnal Kesehatan Lingkungan, pp. 2(2):129-142, 2006.

[8] N. Cahyani, Djamar dan Sulistino, "Heavy Metal Contain $\mathrm{Pb}, \mathrm{Hg}, \mathrm{Cd}$ and $\mathrm{Cu}$ in Whiting Fish (Sillago sihama) Muscle in Estuary of Donan River, Cilacap, Central Java," JPHPI, pp. 19(3):267-276, 2016.

[9] K. L. Taufik, "Kualitas air Hulu dan Tengah Sungai Ciliwung Kabupaten Bogor Jawa Barat.[skripsi]," Bogor, (ID): Institut Pertanian Bogor, 2003. 